\title{
Response to governmental COVID-19 restrictions: the role of informal institutions
}

\author{
Katarzyna Bentkowska \\ Warsaw School of Economics, Institute of Markets and Competition, Warsaw, Poland \\ Corresponding author. Email: kbent@sgh.waw.pl
}

(Received 16 December 2020; revised 29 March 2021; accepted 2 April 2021; first published online 26 April 2021)

\begin{abstract}
This paper explains how informal institutions influence the reaction to the COVID-19 pandemic and the response to formal restrictions. I claim that it is not enough to introduce countermeasures, as individuals must follow them if they are to be effective. The acceptance of such measures is reflected in individuals' degrees of mobility decrease and contact reduction, the aims of governmental restrictions. I identify a group of attitudes connected with individuals' responses that differ across countries. They are associated with social relations and approaches to dealing with problems. The analysis confirms that formal restrictions can be seen as successful only if they are supported by strong informal institutions. In some cases, they even define individuals' reactions more than formal recommendations. The findings are useful not only for explaining the special case of reaction to pandemic restrictions but also for investigating what generally determines individuals' compliance with formal rules.
\end{abstract}

Key words: COVID-19 pandemic; formal institutions; informal institutions; institutional consistency; institutional effectiveness

\section{Introduction}

In 2020, countries unexpectedly faced a new challenge - the COVID-19 pandemic - and they had to take countermeasures to address it. The levels of restrictions imposed varied across countries. However, implementing restrictions does not automatically mean that they are respected. Laws can become rules only if they are not ignored and become customary (Hodgson, 2006). For the fight against the pandemic to be effective, people must adapt and follow the restrictions. If individuals do not accept restrictions and continue to behave as they always have, the pandemic will spread more easily, with severe social and economic consequences. Countries, therefore, differ not only in the regulations they impose but also in the degree to which their regulations are respected. An important question arises here - what determines societies' reactions to the pandemic and the degree of compliance with restrictions?

Answers can be found in the functioning of institutions in a given country. Institutions, as the rules of the game, impose constraints on human interactions (North, 1994: 3). According to the oft-cited interpretation of North (1994), institutions establish important formal constraints, which are written down, introduced and enforced by the state and can thus be seen as laws. However, their effectiveness depends strongly on deeply rooted informal constraints. These are unwritten codes of conduct, traditions, customs, behavioural norms, sanctions and taboos that are created through interaction between individuals and exist independently of the state. In addition, language can be seen as a fundamental institution predicating all others (Searle, 2005). Informal institutions embody societies' mentality and perceptions of the world and current events. They can be reflected in different dimensions, such as 
culture or level of trust in the society. As codes of conduct rooted in people's consciousness, they tend to last a long time and are insensitive to deliberate change. Specifically, I define formal institutions as legal in nature, while informal institutions are nonlegal norms and rules. Informal institutions can strengthen the impact of formal rules, weaken them or even make them inoperable. However, the delineation between formal and informal institutions is often not clear because they may be developed simultaneously and are complementary. They interact and cannot exist independently, as explained in more detail below. Both types of institutions are supervised by enforcement mechanisms. These three elements shape economic performance (North, 1994). To evaluate such performance, we need to understand the actual implementation of formal constraints (Voigt, 2013). However, institutions do not only constrain individuals but also allow behaviour as 'they enable choices and actions that otherwise would not exist' (Hodgson, 2003: 163; Hodgson, 2006; Searle, 2005). The enabling role of institutions is crucial in the case of the pandemic. Habits are the constructive material of institutions (Hodgson, 2003: 164). However, in the case of the pandemic, societies lacked those deeply rooted habits and faced extensive uncertainty. Under such circumstances, state restrictions had some reassuring roles and enabled people to acquire new habits (or change existing ones) and deal with the unprecedented situation. Those newly established habits created a basis for new beliefs and stimulated different actions. Therefore, restrictions constructed a framework on which people could develop behaviours helpful in combatting the disease, e.g. distancing from others in public places.

Interactions between institutions make it difficult to implement formal rules and anticipate how they will work. Different informal institutions and enforcement mechanisms may yield different outcomes. This is true for institutions designed to support general economic development as well as for specific solutions such as rules implemented to fight the pandemic. In my analysis, I focus on the interaction of formal and informal institutions. As Eggertsson (2006: 18) noted, individuals mainly oppose new rules if they adversely affect their material interests or conflict with valued cultural rules or if the individuals themselves believe that the rules are unlikely to have the effect intended by authorities. All the aforementioned reasons can be seen in the case of perceptions of the governmental responses to the COVID-19 outbreak.

An important observation for the analysis can also be found in the path dependence concept, which suggests that institutional arrangements depend on the past (North, 1994). As institutional systems are formed along a path on which subsequent events depend on each other, the currently available choices are determined by former circumstances. The path dependence concept is generally used to explain the current development situation based on past conditions or events (Acemoglu and Robinson, 2012; Acemoglu et al., 2001, 2002, 2005; North 1994, 2005) or to discuss the outcomes of different reforms (Boettke et al., 2008; Chavance, 2008; Chavance and Magnin, 2000). However, this logic is important for dealing with the pandemic. As all countries have a starting point connected with the existing economic and social situation, their response to the pandemic and ability to implement countermeasures differ.

To control the outbreak, governments introduced restrictions and in doing so created formal rules. These concerned, for example, closing workplaces and schools, reducing the size of gatherings or limiting travel. The scale of these restrictions varied by country and changed over time. Nevertheless, individuals reacted in different ways to the pandemic and the restrictions. This difference resulted in a decrease in the level of mobility and the limiting of interpersonal contact. It is important to investigate which individual attitudes determined these reactions, as doing so could reveal more generally what determines individuals' acceptance of formal rules.

Surely some explanation for the degree of compliance with the restrictions can be sought in the scale of the pandemic. Its first wave hit countries with different strengths - Western Europe suffered more severely. Eastern European countries could make use of their western neighbours' experience and had more time for a balanced response. Even if implemented restrictions were quite similar at the beginning, people's attitude towards the pandemic depended on their observations from their own country. Moreover, a society's wealth and its distribution among different groups had some impact. Reducing mobility and refraining from leaving home imply significant economic costs. Severe restrictions are easier to comply with from a stable financial situation. Even despite greater 
risk exposure, some precarious groups in society may decide to continue working feeling they have no choice. This situation is especially problematic if the mitigating policy response is missing or not well addressed, suffering from unequal distribution. However, I believe these circumstances are only part of the explanation, though they cannot be disregarded and I deal with them as well.

Informal institutions are rarely the subject of analysis. Consequently, practical means of assessing them have not been established and their functioning and role remain unclear, though there is a growing consensus on their importance (Boettke et al., 2008; Chavance, 2008; Glaeser et al, 2004; Helmke and Levitsky, 2004; Leković, 2011; Pejovich, 1999; Platje, 2008; Williamson, 2009; Williamson and Kerekes, 2011). Good institutional analysis requires the examination of both institutional components. I claim that societies' response to the pandemic and the effectiveness of the formal rules designed to combat it depend on deeply rooted informal institutions.

The recent events caused by the COVID-19 outbreak offer an unprecedented opportunity to examine how institutions function in the case of a single event, allowing an analysis of whether they cooperated and created a consistent response to the unexpected challenge.

This paper contributes to the literature on the role of informal institutions. However, unlike prior studies, it focuses not on matters connected with economic development or reform outcomes but addresses the efficiency of newly introduced formal institutions according to their compliance with informal institutions. Thus, it draws attention to the links between the institutions and the various results of their operation. As the paper analyses the effectiveness of existing institutional arrangements in different countries, it can also be seen as building on works involving comparative institutional analysis.

The paper is structured as follows. Section 2 describes the role of informal institutions in economic activities and explains the difficulties in their analysis. Section 3 explains my approach to the comparative analysis of societies' response to governmental restrictions and describes the empirical proxies of informal institutions. It also classifies the countries according to the severity of the restrictions and decline in mobility. Section 4 presents the results of the empirical analysis and explains the differences in societal responses. Section 5 presents the conclusions.

\section{Role of informal institutions}

The role of institutions in economic development is currently beyond doubt. Institutions have been frequently subjected to various analyses confirming their role in economic development (Acemoglu and Robinson, 2012; Acemoglu et al., 2014; Gradstein, 2008; Knack and Keefer, 1995; Kovac and Spruk, 2016; Kuncic, 2014; Rodrik et al., 2004) and in more detailed but related problems, such as inequality (Cervellati et al., 2008; Chong and Gradstein, 2019; Kyriacou and Velasquez, 2015; Holcombe and Boudreaux, 2016; Sonin, 2003). These papers, however, focus primarily on formal institutions. The reason is clear - formal institutions are easier to identify, operationalise, analyse and evaluate. This does not mean, however, that they are more significant. Recently, informal institutions have begun attracting more attention, and their role in economic development has begun to be considered no less important than that of formal institutions.

Despite growing interest in informal institutions, we still know little about their nature, origins and consequences in different settings. As informal rules result from the acquired experience and value systems of individuals, they are created through interpersonal interaction and often remain unconscious. According to Ostrom (2005: 4-5), institutions govern the whole range of experience in contemporary life, and even though we implicitly make sense of most of them, 'frequently, we are not even conscious of all of the rules, norms, and strategies we follow'. This is especially true for informal institutions. The challenge of investigating informal institutions lies in their nature. Williamson's classification of institutions based on their embeddedness describes informal institutions as those that have developed over the course of hundreds or thousands of years (Williamson, 2000). As such, they are difficult to study.

There is even a lack of consensus regarding what informal institutions actually are. Consequently, they are operationalised differently in different studies. Controversies are emerging even in the case of 
formal institutions, which are considered easier to measure (Glaeser et al., 2004; Voigt, 2013). These doubts raise questions regarding whether the proxies for institutions truly measure them or reflect their outcomes only. Nevertheless, it remains even more unclear how informal institutions can be investigated (Voigt, 2018).

Finally, data on proxies connected with informal institutions are very scarce, cover short periods and are often unsuitable for extensive comparative analysis. In regard to such analysis or the measurement of certain institutional indicators, informal institutions are excluded due to the abovementioned problems (Kuncic, 2014: 139). If some aspects connected with informal institutions are measured, they remain parts of larger aggregates, and their informal nature is not stressed (for instance, Eicher and Rohn, 2007).

Many papers concerning informal institutions are based on descriptive studies of institutional arrangements in a few countries, possibly in a particular geographical region, that often adopt a broad historical perspective (for instance, Acemoglu et al., 2001, 2005). Such research should not be neglected, as it contributes significantly to a better awareness of informal institutions. Even in papers drawing attention to informal institutions in general, the analyses are often descriptive. Nevertheless, they provide important insight into informal institutions' role and differential performance based on the cooperation between formal and informal institutions (Helmke and Levitsky, 2004; Leković, 2011; Pejovich, 1999; Platje, 2008). Empirical studies of informal institutions are less common, but their results support the important role of informal institutions (Aron, 2000; Casson et al., 2010; Cruz-García and Peiró-Palomino, 2019) and even their primacy (Glaeser et al., 2004; Williamson, 2009). For instance, investigating the interactions between formal and informal institutions, Williamson (2009) confirms that countries with stronger informal institutions achieve higher levels of economic development. The influence of informal institutions is here more pronounced than that of commonly stressed formal norms.

Insights on how to evaluate certain components of informal institutions can be found in the literature concerning trust (Tabellini, 2010; Williamson, 2009; Williamson and Kerekes, 2011), social capital (Knack and Keefer, 1997) and the values transmitted to children, such as obedience, self-determination or respect (Tabellini, 2010; Williamson, 2009; Williamson and Kerekes, 2011). Such measures of informal institutions are sometimes criticised as subjective or not directly reflecting them. However, they still provide important insights into individuals' beliefs, behaviours and perceptions of reality, even if they do not perfectly reflect the whole range of informal institutions. Even if we see these measures as outcomes of institutions, they still bring us closer to understanding how actual institutions work. Such variables are shaped not only by deeply rooted informal institutions but also by the quality and performance of formal institutions. For example, lack of trust in the government can be the result of certain cultural traits connected with general distrust but also of poor performance observed in everyday life. A similar view is stressed by Voigt (2018). However, such problems also relate to formal institutions because, as Hodgson (2006) states, even formal rules cannot be seen as purely formal, since, to operate, they depend on informal institutions. The proxies analysed in my paper might be seen as the outcomes of informal institutions, not pure informal institutions themselves. However, as we do not have better proxies to describe informal institutions directly, despite the mentioned problems, I shall refer to my variables as 'informal institutions'.

I will also focus on some measures of trust and social capital in my analysis. However, I will also select other proxies of great importance in my case, such as interest in current events, external assistance needs or support for populism. I focus on more detailed proxies of informal constraints initially, and later, I try to find more general dimensions by aggregating them.

\section{Data and methodology}

The scope of restrictions introduced by governments is measured with the Stringency Index - part of the Oxford COVID-19 Government Response Tracker (OxCGRT). It estimates indices such as school 
and workplace closure, restrictions on gathering size, restrictions on travelling both internally and internationally, and stay-at-home requirements (Hale et al., 2020).

The restrictions aim to separate people from each other and therefore to reduce disease spread. I assume that the restrictions are obeyed if people reduce their mobility and stay at home more often. To measure the response to the restrictions, I adopt the residential data from Google Community Mobility Reports, which provide insights into what has changed in response to policies aimed at combating COVID-19 (Google LLC, 2020). I focus on the residential index, which rates the mobility trends for places of residence. ${ }^{1} \mathrm{~A}$ higher value indicates that people refrained from moving and decided to stay at home.

Other data sources are the European Values Study 2017-2021 (EVS, 2020) and the Legatum Prosperity Index 2019 (2020). They were selected to provide current insights into societies' attitudes that may explain the response to the pandemic and the restrictions. They reflect individual beliefs, attitudes, norms, and values and the existing pattern of relations in society. Detailed information about the selected data will be provided later in the paper.

For the cross-national analysis, I choose 27 European countries with all the necessary data available. They compose a group with relatively similar economic conditions and close connections. Moreover, the confirmation of the first COVID-19 cases and further outbreaks in Europe started at more or less the same time - approximately February/March. Therefore, government restrictions were also introduced at a similar time. This makes both the restrictions and the reactions to them highly comparable.

The preliminary exploration investigates the scope of the restrictions and the degree of mobility changes in two 5-day periods from the first wave of COVID:

1. 30 March-3 April - peak

2. 6-10 July - nadir

Both periods comprise weekdays, as people have different routines during the weekends, so it is difficult to evaluate changes in their mobility.

The first period represents the peak of both the Stringency Index and the residential index. All analysed countries had already introduced strict policies to control the outbreak. The peak period was also characterised by the sharpest mobility decline.

The second period represents the nadir. Restrictions were being relaxed, but as the Stringency Index shows, all countries continued to enforce some restrictions. Residential changes indicate that people increased their mobility.

Having two periods, I compare the coefficient of variation for the Stringency Index and residential changes in the countries selected for the analysis. For the peak period, the coefficients of variation are equal to $22 \%$ and $26 \%$. Therefore, both the governments' responses and the societies' reactions were similar. However, for the nadir, there are much larger differences, as the coefficient of variation for the Stringency Index rises to $27 \%$ and for residential changes to $101 \%$. As I aim to investigate the societal response to the restrictions, further analysis is based on the nadir period. Because of weakening but still existing restrictions, people increased their mobility, and their reactions across countries became less similar.

In the next step, I determine the position of every country on a matrix defined by the scope of governmental restrictions, measured by the Stringency Index, and the societal response, measured by the residential data, for the nadir period (Figure 1). It should be stressed that I am looking for the relative position of the countries, as I seek to assess the adequacy of the societal response to the restrictions in force. I do not try to measure the appropriateness of governments' or societies' reactions to the COVID-19 situation or to determine the reason for restrictions. Moreover, the results of the countries

\footnotetext{
${ }^{1}$ Everyday residential data are compared relative to a baseline given as a median value of the corresponding day of the week within the five-week period before the pandemic outbreak: from 3 January to 6 February 2020.
} 


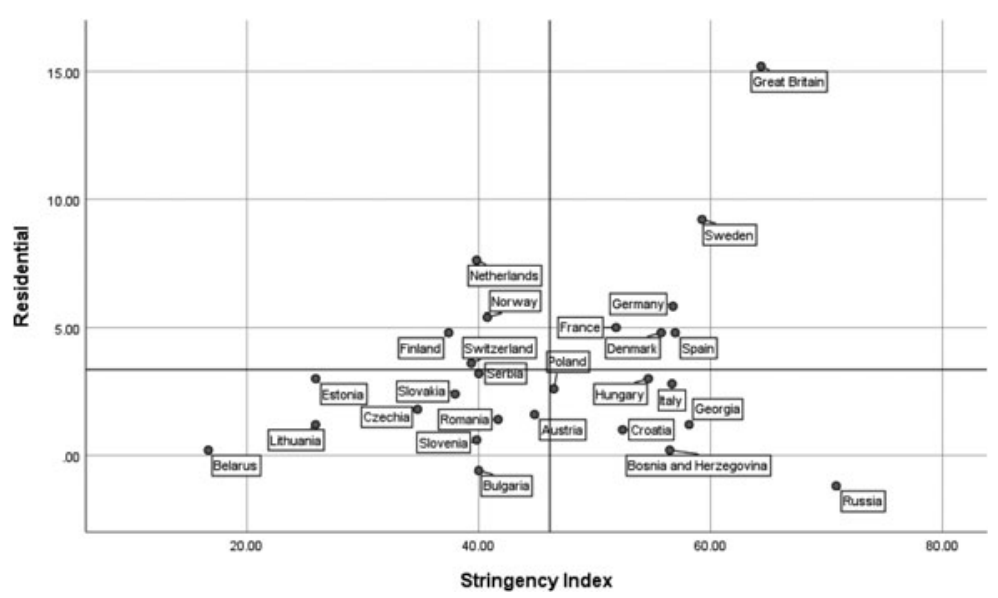

Figure 1. Country matrix based on the Stringency Index and residential change for the nadir period - 6-10 July.

refer to a short period and cannot be seen as an evaluation of the strength of governmental reactions throughout the whole pandemic. The results may differ from the general assessment of reactions to the pandemic in the different countries. I aim to determine to what extent the reactions of the government and society were compatible. Therefore, the key to grouping the countries lies in finding their position relative to the average reaction. I calculate the average values of the Stringency Index and residential change. The countries are marked on the matrix according to the combination of their average Stringency Index and average residential change for the nadir period. As a result, they are divided into four groups (Table 1).

The first group comprises countries where the restrictions remained relatively strict; however, the societal response was relatively weak. The residential change value is below average, which indicates that people did not follow the rules and did not decrease their mobility as markedly as people in other countries. Accordingly, the formal institutions were quite strong, while the response was weak. The informal attitudes of society to some extent worked against the formal institutions. Therefore, this institutional outcome is characterised by inconsistency between the institutions and a lack of complementarity.

The second group represents countries with relatively severe restrictions and a sharp decline in mobility. Therefore, strong formal institutions were combined with a strong response by society. This phenomenon results in a combination of coherent institutions.

The third group includes countries where the restrictions were relatively weak. Nonetheless, the societies responded to the situation relatively strongly. In this scenario, informal attitudes produced stronger responses than the formal institution required. The institutions can thus be described as complementary. In such a situation, the government may interfere less and restrain from severe restrictions, as society will act responsibly on its own. Ostrom's works indicated that solutions created by communities may be surprisingly effective and sometimes better than exogenous regulations (Ostrom, 1990, 2000; Ostom et al., 1992, 1999). The differential performance of institutions introduced exogenously or endogenously is stressed in other works as well (Boettke et al., 2008; Chong and Gradstein, 2018; Eggertsson, 2006).

Finally, the fourth group represents countries with weak restrictions and weak societal reactions. The mobility decline was relatively low; however, the government response was less strict than average. Again, these institutional outcomes are characterised by the institutions' compatibility, but the equilibrium is at lower degrees of institutional strength. There is no complementarity between the formal and informal institutions. The societies' actions do not exceed governmental expectations.

The empirical proxies of informal institutions have to be carefully selected so that they can offer a comprehensive explanation of the societies' different reactions. They are associated with individuals' 
Table 1. Country classification according to the Stringency Index and residential change

\begin{tabular}{cccc}
\hline Group 1 & Group 2 & Group 3 & Group 4 \\
\hline $\begin{array}{c}\text { Strong restrictions, weak } \\
\text { reaction }\end{array}$ & $\begin{array}{c}\text { Strong restrictions, } \\
\text { strong reaction }\end{array}$ & $\begin{array}{c}\text { Weak restrictions, } \\
\text { strong reaction }\end{array}$ & $\begin{array}{c}\text { Weak restrictions, weak } \\
\text { reaction }\end{array}$ \\
\hline $\begin{array}{c}\text { Bosnia and Herzegovina, } \\
\text { Croatia, Georgia, }\end{array}$ & $\begin{array}{c}\text { Denmark, France, } \\
\text { Germany, Spain, }\end{array}$ & $\begin{array}{c}\text { Finland, } \\
\text { Netherlands, }\end{array}$ & $\begin{array}{c}\text { Austria, Belarus, Bulgaria, } \\
\text { Czechia, Estonia, Lithuania, } \\
\text { Hungary, Italy, Poland, }\end{array}$ \\
Russia & Sweden, United & Norway, & Romania, Serbia, Slovak \\
Kingdom & Switzerland & Republic, Slovenia \\
\hline
\end{tabular}

relations with society, ability to cope with the situation and assessment of the different authorities responsible for combating the pandemic.

The first group of variables is connected with trust. I do not rely on available aggregate measures of trust, as for the analysis, it is important to capture different kinds of trust. Rothstein and Stolle (2008) point out that individuals make distinctions between institutions and have different levels of confidence in them. Trust variables include

- 'trust in others', which represents the most general type of trust

- 'trust in the government', as it is in charge of measures for controlling the outbreak, their enforcement and information policy

- 'trust in parliament', as it is also responsible for the established law

- 'trust in the healthcare system', as it deals with the sick and provides information about the development of the outbreak

- 'trust in the press', as it should be an independent and reliable source of information about the situation

Data from the EVS are utilised to quantify the trust components. Trust in others is measured, as is commonly done in the literature, with the question 'Generally speaking, would you say that most people can be trusted or that you can't be too careful in dealing with people?'. Proxies for trust in the government, parliament, healthcare system and press are quantified with the question 'How much confidence do you have in each of them?'. Generally, it is stressed that trust enables individuals to exchange goods at a lower cost (for instance, Williamson and Kerekes, 2011: 547). However, this motivation is more relevant to issues concerning economic development. Here, of greater importance is the role of trust in encouraging desired individual behaviours. Lower levels of trust may result in greater resistance to new formal constraints. Societies characterised by higher levels of trust perceive government officials as more trustworthy and their policies as more credible (Knack and Keefer, 1997: 1253). Trust is said to be the key ingredient of the relation between citizens and public institutions, and it allows each side to believe that the other side will comply with the rules (Camussi and Mancini, 2019: 500). However, there are other implications of trust as well. Trust in the healthcare system reveals not only trust in official recommendations but also belief in its capacity during the pandemic and certainty that it will provide assistance. Trust in others reflects the anticipated response of others to the restrictions - with lower trust, individuals may expect others to break the rules. Moreover, societies with higher levels of trust are less dependent on formal institutions to enforce agreements (Knack and Keefer, 1997: 1253). Therefore, individuals are more inclined to work out their own response to challenges such as the pandemic. Trust is considered to be an important part of social capital (Rothstein and Stolle, 2008).

The second group of variables reflects interest in current events and awareness of the situation's gravity. They can be seen as informal institutions as they mirror societies' attitudes towards knowledge and its active acquisition. They show whether people tend to be passive and ready to accept the 
situation without trying to understand it or whether they actively try to make up their minds based on available information. The closest questions related to such attitudes are derived from the EVS: 'How interested would you say you are in politics?' and 'How often do you follow politics in the daily papers?'. The variables are called, respectively, 'interest in the current situation' and 'following daily papers'.

'Resourcefulness' is the proxy showing individuals' attitudes towards life circumstances. In the EVS, individuals indicate which statement is closer to their views - 'Individuals should take more responsibility for providing for themselves' or 'The state should take more responsibility to ensure that everyone is provided for'. In the current situation, it may reflect whether people feel their actions can help control the pandemic or whether they are expecting the state to take care of the situation.

Another important attitude influencing the response to restrictions is support for populism. It can be perceived as informal institutions as it reflects societies susceptibility to easy but distorted promises and solutions. It is also connected with the attitude towards knowledge, critical thinking and the need for a good understanding of the situation. Societies basing their actions on reliable information and being more inclined to critical thinking are less vulnerable to populist theses. In the case of the pandemic, if support for populism is strong or the government is formed by populist parties, there is a threat of less reliable information concerning the gravity of the situation, as the government may prefer to present its actions and their effects in a good light. It may also be less motivated to make unpopular decisions. Moreover, there may be a lack of demand for reliable information, as people are more inclined to trust distorted information. The proxy for 'populism support' is derived from the Timbro Authoritarian Populism Index. It reflects support for a populist party in the last national parliamentary election and the role the party has in parliament. Problems with populism can be linked to Acemoglu's observations on the reasons for the emergence and maintenance of inefficient institutions (Acemoglu, 2006: 376). As political elites tend to determine policies according to their interests and preferences, they may also form a response to the pandemic in such a manner. It is especially striking if they lack institutional constraints, which may be the case in countries with strong support for populism. Growing support is considered to be connected with the weakness of democratic institutions (Acemoglu et al., 2013; Ádam, 2020), growing distrust in them (Algan et al., 2017; Guiso et al., 2017) and low levels of social capital (Boeri et al., 2018).

The Populism Index is calculated only for democracies. Nondemocracies and semiauthoritarian countries are excluded from evaluation (Timbro, 2019). This is the case for Bosnia and Herzegovina, Georgia, Russia and Belarus. Confirmation of this can be found in the Democracy Index (2019). Based on the scores obtained, each country is classified as one of four types of regimes: full democracy, flawed democracy, hybrid regime or authoritarian regime. The countries evaluated by the Timbro are either full democracies or flawed democracies. However, Bosnia and Herzegovina as well as Georgia are classified as hybrid regimes, while Russia and Belarus are authoritarian regimes. Based on this evaluation, for further analysis, Bosnia and Georgia received 80 points for populism, and Russia and Belarus received 100 points.

The last group of variables reflects individuals' connection with society and participation in social life. These variables can be measured via social capital indicators derived from the Legatum Prosperity Index (2019), e.g. 'personal and family relationships', 'social networks', and 'civic and social participation'. 'Personal and family relationships' describes relations with those closest to one, while 'social networks' reflects relations with those with whom one is not close. 'Civic and social participation' represents the most general ties. In the literature, social capital is recognised as encouraging solutions to collective problems (Knack and Keefer, 1997; Voigt, 2018). Societies with integrated citizens who are involved in the system have higher levels of trust in governmental institutions (Christensen and Lægreid, 2005: 505). Stronger relations with all dimensions of society may facilitate problem resolution and bottom-up actions to fight the pandemic. Moreover, socialisation and feeling part of a community may encourage individuals to act as reasonably as others. Existing informal sanctions reduce the willingness to act opportunistically (Zak and Knack, 2001). 


\section{Empirical results}

To verify whether the identified societal attitudes differentiate the four groups of countries, I run a series of one-way analyses of variance (ANOVAs) for independent groups for 12 variables. ${ }^{2}$ The results indicate that there are differences in the mean values among the groups for 11 variables, which confirms my expectations. Nevertheless, the $F$ statistic is insignificant for trust in the press, so it is omitted from further analysis.

The $F$ statistics confirm that there are some differences between the groups but do not indicate which groups. I therefore perform a post hoc analysis with two different tests. I choose a conservative Scheffe test and a more liberal Gabriel test. Generalising the post hoc test results, we can conclude that groups 1 and 4 are more similar. There are also similarities between groups 2 and 3 . However, if we compare groups 1 and 4 with groups 2 and 3, there are significant differences. What distinguishes groups 1 and 4 are formal institutions. The same is true for groups 2 and 3. However, if we compare groups 1 and 4 with groups 2 and 3, there is a difference in mobility changes, which informal institutions are expected to influence.

Group 1, with a weak response to strict regulations, has the lowest level of all the forms of trust. The variables reflecting individuals' connections with society and participation in social life also have low values. The variables reflecting interest in the current situation and resourcefulness have the lowest scores. Very distinctive here is the support for populism. Group 1 comprises three countries not evaluated by Timbro; however, the scores for the remaining countries are very high (except from Croatia). Populist or authoritarian governments may overstate their successes and avoid presenting the real situation. This results in a lack of information about the real state of the outbreak and low awareness in society. A low level of trust results in a weak response to recommendations or even restrictions designed to control the outbreak. Moreover, individuals lack interest in the current situation, so they may not try to investigate what is happening with the pandemic. As a consequence, they are not aware of how they should act. Since they lack close relations with society and prefer that the state take action, they cannot respond properly to the situation.

Group 4 is quite similar to group 1 but has less extreme results. The countries here also score low on trust, social ties and interest in the current situation, but less markedly. The relatively high level of resourcefulness shows that individuals do not expect help from the state. Moreover, the support for populism is significantly lower, so members of this group may be less susceptible to overstated promises. The societies in this group also do not seem to work out their own response; however, we cannot say that they do not follow the formal rules. The formal and informal institutions seem to be compatible even though they are relatively weak. The societies do not do more than they are asked to.

Group 2, where people respond to severe restrictions quite strongly, is characterised by high levels of trust and strong social ties. The societies in this group seem to be interested in the current situation, which may result in greater awareness of disease spread and better support for necessary measures. Relatively low levels of resourcefulness may indicate that individuals expect the state to take the initiative. This result proves the need for strong governmental responses and strict regulations. The support for populism is the lowest, which may be the result of better political awareness. The government is more obliged to take responsible steps, but it can expect them to be followed.

Group 3 has similar attitudes to those of group 2, but here, the individuals seem to take matters into their own hands more, and their actions go beyond the formal rules. Government restrictions are less needed since individuals act very responsibly, possibly because this group has the highest levels of trust and the strongest social ties. Individuals are also most interested in the current situation, but unlike their counterparts from group 2, they do not feel that the state should take all the responsibility, so they act on their own. Such actions are supported by strong social capital.

\footnotetext{
${ }^{2}$ The data requirements for ANOVA are met. The Shapiro-Wilk test confirms the normal distribution of the proxies in almost every group. Levene's test confirms the homogeneity of variance in each group.
} 


\section{Factor analysis}

To deepen the analysis, I seek to determine whether the variables can form broader factors describing the informal institutions influencing the response to restrictions. Therefore, I carry out a factor analysis to identify independent latent variables and reduce the number of proxies. ${ }^{3}$ The initial solutions with the Kaiser criterion and scree plot indicate that three factors explain $84 \%$ of the variance. For further analysis considering those three factors, I use the Varimax orthogonal rotation. The results show which variables compose each of the factors and how strongly they load on these factors.

Finally, based on the rotated components matrix, I obtain three factors arranged according to the size of the variables' factor loadings.

Factor 1:

- trust in the government

- trust in parliament

- trust in others

- interest in the current situation

- following daily papers

Factor 2:

- resourcefulness

- populism support

- personal and family relationships

Factor 3:

- social networks

- civic and social participation

These factors become my new variables. The size of the variables' factor loadings is considered when calculating the value of each factor.

Factor 1 comprises all variables connected with trust and interest in current events. It describes 'trust and knowledge', which reflects the level of trust in society and the active acquisition of information on its functioning.

Factor 2 is more difficult to describe at first glance. However, it describes individual expectations concerning how problems should be managed. One may expect that the state will take care of everything or that one has to act on one's own. Strong relations with one's most trusted social ties, i.e. family and friends, can be helpful when coping with problems. As far as the state's role is concerned, individuals may have reasonable expectations or be tempted by unreliable promises. In the first case, there will be low support for populism, while in the latter, such support may be strong. Thus, Factor 2 is labelled 'dealing with problems'.

Factor 3 contains 'civic and social participation', which reflects participation in social life, and 'social networks', indicating connections with others in one's environment. We may call it 'relations in society' as it is connected with the willingness to participate in community life and promote common prosperity.

Once more, I use an ANOVA to check whether the factors differentiate the four groups of countries. The ANOVA ${ }^{4}$ results are statistically significant, supporting the assumption of differences between the

\footnotetext{
${ }^{3}$ As the initial analysis indicated that the variable 'trust in the healthcare system' correlates with two factors, I exclude it from the analysis and focus on 10 variables.

${ }^{4}$ The Shapiro-Wilk test confirms the normal distribution of the variables in most of the groups. Levene's test confirms the homogeneity of variance in each group.
} 


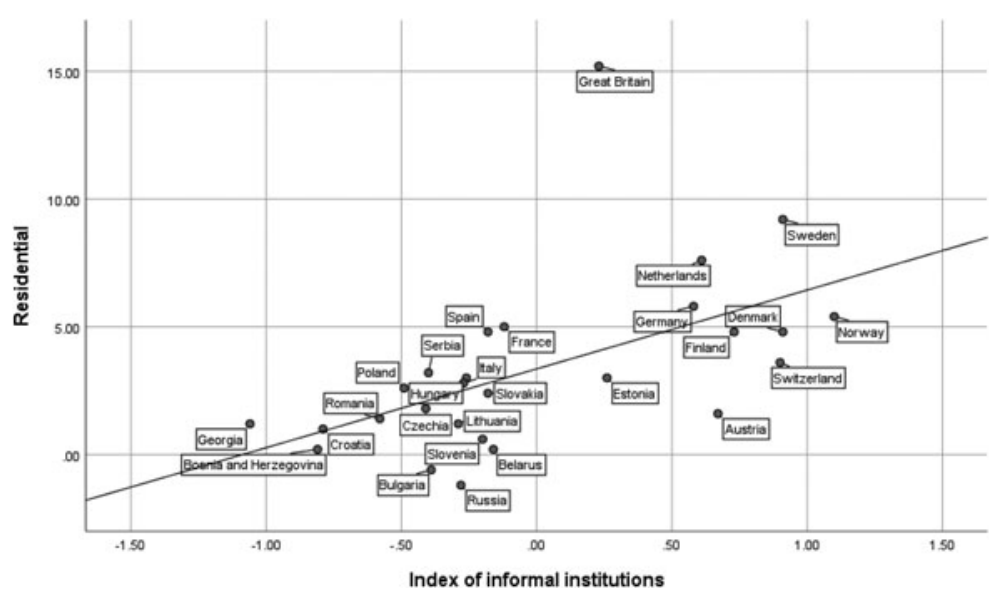

Figure 2. Relationship between the index of informal institutions and residential change for the nadir period.

groups. Similar results are obtained with the Kruskal-Wallis test (used in case of a deviation from a normal distribution). The post hoc tests' results can be explained as follows: residents in the countries in groups 1 and 4 have worse trust and knowledge, so they cannot respond properly to the challenges posed by the pandemic. This is especially problematic in the countries in group 1, where individuals feel more dependent on the state and are tempted by populism or even depend on authoritarian governments. Despite high expectations of state support, lack of trust and weakly developed relations cause these individuals to not follow the restrictions implemented by the government. In contrast, individuals in the countries in groups 2 and 3 have better relations, are better able to deal with problems and can respond to the pandemic properly - they either follow the restrictions or exceed obligatory requirements. In their case, we can clearly see the role of institutions in enabling people's behaviours.

\section{Index of informal institutions}

Since three factors distinguish the groups, I construct an index of informal institutions. It is calculated as the weighted average of the three factors. The weights are based on the per cent of the variance explained by these factors. ${ }^{5}$

To determine whether the differences in informal institutions cause different societal responses I investigate the correlation between the index of informal institutions and the decline in mobility for the nadir period (Figure 2). I use Spearman's rank correlation, as the distribution of the variable deviates from normal. Spearman's $\rho=0.679, p<0.001$, confirming a strong positive correlation between the variables. A high decrease in mobility is accompanied by a high informal institutions index.

Regardless, a question remains - does the shape of informal institutions explain whether the extent to which people declined mobility matches government formal restrictions. On the initial matrix concerning the Stringency Index and residential data, I define the fit line (Figure 3). Countries above the line are characterised by better informal institutions, i.e. the index is above the average, while countries with an index of informal institutions below the average fall below the fit line (with only four exceptions $^{6}$ ). Such results confirm that informal institutions influence the relation between mobility changes and formal institutions.

\footnotetext{
${ }^{5}$ As together they explain $84 \%$ of the variance, it is equal to 1 . Hence, Factor 1, explaining $39 \%$, has a weight of 0.465 ; Factor 2, explaining $24.5 \%$, has a weight of 0.29 ; Factor 3, explaining $20.5 \%$, has a weight of 0.245 . Higher index values should be interpreted as better outcomes.

${ }^{6}$ France and Spain, with relatively weaker informal institutions, are above the fit line. Austria, with relatively stronger informal institutions, is below the fit line. Serbia, with relatively weak informal institutions, is above the fit line.
} 


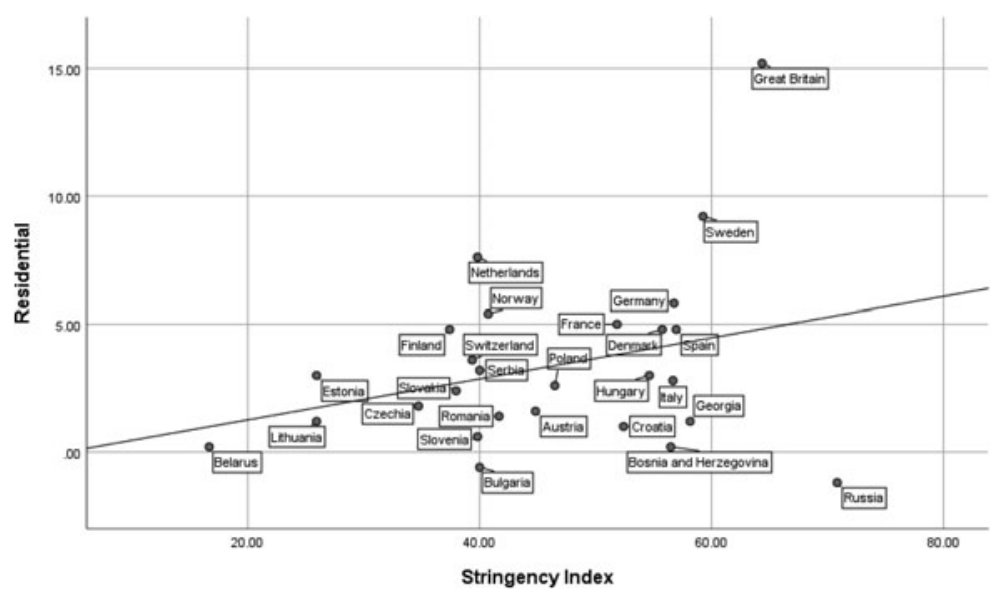

Figure 3. Country matrix based on the Stringency Index and residential change for the nadir period - 6-10 July with the fit line.

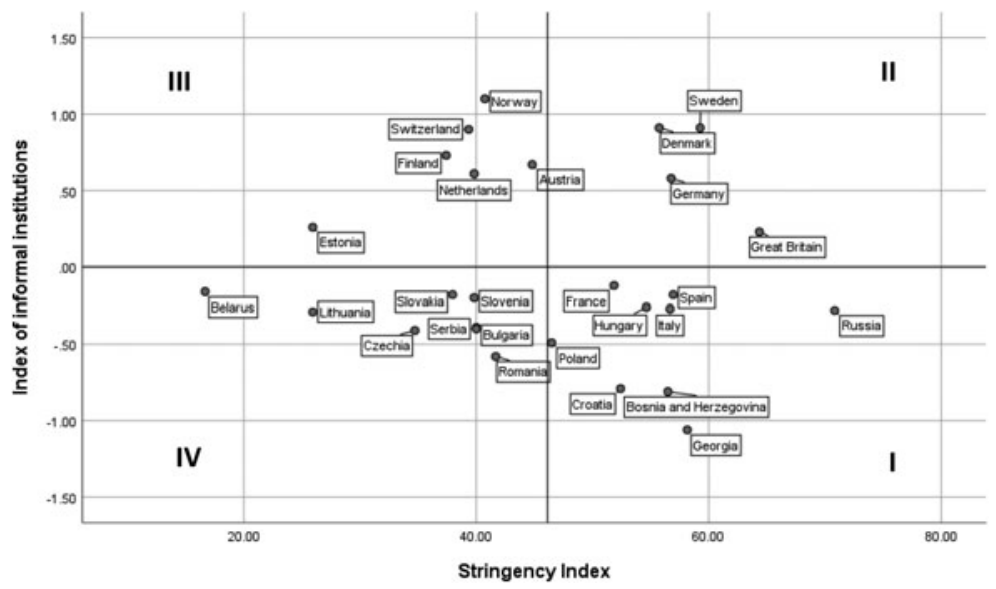

Figure 4. Country matrix based on the Stringency Index and the index of informal institutions for the nadir period.

Furthermore, similar to my initial concept, I determine the position of every country on a matrix defined by the Stringency Index and the index of informal institutions (Figure 4). Again, I calculate the average values of these two variables and divide the countries into four groups: strong restrictions and strong informal institutions, strong restrictions and weak informal institutions, weak restrictions and strong informal institutions and weak restrictions and weak informal institutions. The results show that the division almost perfectly matches the initial division based on the relative strength of the Stringency Index and residential changes (Figure 1). Only four countries fall into a different group, as Austria and Estonia have stronger informal institutions than is indicated by their relatively weak decline in mobility, while France and Spain have weaker informal institutions.

For groups 2 and 4, the extent to which people declined mobility matches government formal restrictions. This result is explained by informal institutions, which, in both cases, comply with formal rules, however, on different levels of equilibrium. In group 2, with stronger informal institutions, this level is higher, while, in group 2, with weaker informal institutions, the equilibrium is lower. For group 3 , the match between mobility decline and formal restrictions is not so straightforward, but it can be explained by informal institutions. Here, people accepted the formal rules but complemented them 
thanks to strong informal institutions and exceeded governments' expectations. There is definitely no match between mobility decline and formal restrictions in group 1. People here did not follow relatively strict restrictions nor did they change their mobility significantly. Such a result can be explained by weak informal institutions.

\section{Robustness tests}

I employ several robustness tests that confirm my empirical results.

First, I check the correlation between residential change and the Stringency Index. Spearman's rank correlation test confirms that there is such a relationship for the peak period $(0.626 ; p<0.001)$. Most importantly, there is no statistically significant relationship between residential change and the Stringency Index for the nadir period. Therefore, other factors must influence mobility changes.

As a test, I also look for explanations of the different reactions to restrictions in factors commonly appearing in analyses of the pandemic. ${ }^{7}$ These may be connected with disease spread, so I consider such variables, calculated as means for the nadir period, as 'new cases per million', 'new deaths on COVID per million', 'total cases per million' and 'total deaths on COVID per million'. As concerns arise whether reported COVID deaths capture the true impact of the coronavirus on mortality, I use the calculations of 'excess deaths' as well. ${ }^{8}$ Moreover, societal reactions may be connected with the risk of serious health problems or even death in a society. Such risk increases with age, so I include the following variables: 'median age in the population' and 'population aged older than 70 '.

Another group of variables possibly determining the mobility changes is connected with different economic situations and government welfare support during the pandemic. Precarious groups of society may feel they cannot afford to give up their work and stay at home as the economic costs of doing so are too high. Hence, I include as tests the level of extreme poverty, poverty gap and Gini Index. The data may not be perfect for my analysis as they do not concern the pandemic directly; however, I believe they reflect the baseline for the country's economic situation in terms of vulnerability to pandemic threats. The shape of a government's mitigating policy may influence people's willingness to stay at home. Therefore, the next variable is the Economic Support Index from OxCGRT, which evaluates the scale of income support and debt/contract relief for households.

Spearman's rank correlation test confirms some relationships. As expected, the relationship is positive between residential change and total deaths on COVID per million (Spearman's $\rho=0.579, p<$ 0.002 ) and excess deaths (Spearman's $\rho=0.443, p<0.05$ ). However, these associations seem weaker than in the case of the index of informal institutions and residential change. There is no confirmed relationship between residential change and total cases per million, new cases per million or new deaths on COVID per million. The decrease in mobility cannot be explained by vulnerability to the disease, as there is no confirmed relationship between residential change and population median age or population aged older than 70 .

Economic inequality also does not seem to explain differences in societies' reactions, as residential change is not associated with extreme poverty, the poverty gap or the Gini index. Similarly, the level of the government's economic support is not confirmed responsible for the degree of mobility reduction.

As another test, I check the correlation between the index of informal institutions and residential change controlling for total deaths on COVID per million as this is the second strongest relation identified and a very intuitive one. The result obtained is a bit lower and equal to 0.563 . Still controlling for total deaths on COVID per million, the variables exhibit a strong positive correlation.

Referring to the different scale of the pandemic in European countries during the first wave of COVID, I check the investigated relationships for one more period - 5-9 October 2020. This period was chosen as, at the beginning of autumn, countries that had not yet suffered severely started to note

\footnotetext{
${ }^{7}$ These data are derived from the data on COVID-19 (Our World in Data, 2020), except for the Gini Index and poverty gap data derived from the World Bank.

${ }^{8}$ Data available for 22 countries.
} 
an increasing number of new cases and deaths. Again, the governments began to tighten the restrictions; however, their levels differed, allowing comparisons. The correlation between the index of informal institutions and the decline in mobility for this period can again be described as high, as Spearman's $\rho=0.632, p<0.001$. This result is stronger than the relation between the Stringency Index and mobility change (0.447). The two matrices were analysed based first on the relative strength of the Stringency Index and residential changes (both for 5-9.10) and second on the relative strength of the Stringency Index (for 5-9.10) and the index of informal institutions. This analysis showed that many countries fall into very similar groups using both classifications (19 of 27). Most of the countries assigned to dissimilar groups are very close to the borderlines. Therefore, such results confirm that informal institutions determine societies' reactions to the pandemic.

\section{Conclusions}

My research evidences the significant role of informal institutions. Though this role has been recognised in the literature, we still lack empirical analysis in this field. Consequently, informal institutions remain an undiscovered element of the institutional system. For formal institutions to be effective, it is crucial to have informal institutions that comply with them or even complement the formal rules. If we want formal institutions to work as intended, we must envisage societies' reactions. Even though it is difficult to intentionally influence informal institutions, knowing their characteristics can be of great help. To some extent, awareness of informal institutions' strengths and weaknesses can improve predictions of institutional performance. In some cases, it can allow the negative influence of informal institutions on formal institutions' acceptance to be mitigated or enhance the positive effects of new rules that are less strict and leave more space for societal initiative.

The paper contributes to a better awareness of informal institutions' role in general and indicates which institutions influence the acceptance of formal institutions. These institutions are associated with different kinds of trust, interest in the current situation, support for populism, relations in society, participation in social life and individuals' resourcefulness. I found that such attitudes influence societies' response to COVID-19 restrictions, as they are connected with the degree of mobility decline. However, they may be crucial to the acceptance of all formal rules.

The reaction to the pandemic and compliance with formal rules can be related to scale, income inequalities and government welfare support. However, these factors do not provide a good, or at least not a full, explanation. Only the number of total deaths on COVID per million and excess deaths are correlated with mobility changes. Nevertheless, the relationship is weaker than in the case of the index of informal institutions. No variable connected with the infection rate is statistically significant for mobility changes. The pandemic scale differed between Western and Eastern European countries during the first wave. Regardless, societies' reactions and compliance with formal restrictions cannot be described only by their vulnerability to the pandemic. Moreover, even if most of the Western countries complied with formal rules more than the Eastern ones did, this behaviour can be explained by the different shape of their informal institutions. In addition, my measures of inequalities and welfare support do not translate into the different changes in mobility.

The findings concerning the relations between formal and informal institutions have some policy implications. Countries with better developed informal institutions can expect their formal rules to be followed. Moreover, in some cases, there is a need for less formal rules as informal institutions may complement them. This situation can decrease the cost of creating and enforcing formal rules. Regardless, the shape of formal institutions is of great importance if people are expected to trust and use them as guidelines in their actions. Conversely, countries with weak informal institutions can expect the effects of their rules to not be as anticipated. The government should be aware of this situation when envisaging the final outcome of its regulations. In countries with weak informal institutions, the effectiveness of formal institutions can be supported by focusing on enforcement mechanisms. If a strong societal response in a short time is crucial, supporting formal institutions with strong execution may be necessary. This is the case during the pandemic, when the desired 
societal reaction involves a significant decline in mobility and reduced social contact. However, in general, creating and maintaining an enforcement mechanism implies a significant cost. Moreover, if the formal rules are not accepted by the society, supporting them with an enforcement mechanism may further undermine trust in the state and prevent social capital development. Therefore, achieving good results without supportive informal institutions is not easy.

Informal institutions may be insensitive to deliberate change. Weak informal institutions will not become strong immediately; however, some improvement is possible, at least in the long run. For example, in the case of the pandemic, comprehensive and reliable information campaigns about the seriousness of the threat and about possible countermeasures and their effects can help to achieve the restrictions' aims and direct individuals' actions in the desired way. Emphasis can also be placed on actions that increase trust in society, even if the effects will not be immediate. Similarly, some actions can foster stronger relations in society. This can be of great importance, especially in countries with a low level of resourcefulness. If individuals cannot deal with problems on their own, they can find help not necessarily from the state but from other members of society. The results also contribute to understanding the negative effects of populism, as societies with higher support for populism are less inclined to follow formal rules.

The conclusions are important beyond the specific case of the COVID-19 outbreak and the response to the related restrictions. Nevertheless, it is a good case for analysis, as the formal institutions were built from scratch in every country and around the same time. They may also be important for the general functioning of the institutional system and for anticipating the outcome of the implementation of new rules in different fields.

\section{References}

Acemoglu, D. (2006), 'Modelling Inefficient Institutions', in R. Blundell, W. K. Newey, and T. Persson (eds), Advances in Economics and Econometrics. Theory and Applications, Ninth World Congress, New York: Cambridge University Press, pp. 341-380.

Acemoglu, D. and J. A. Robinson (2012), Why Nations Fail, New York: Crown Publishing Group.

Acemoglu, D., G. Egorov and K. Sonin (2013), 'A Political Theory of Populism', Quarterly Journal of Economics, 128(2): 771-805.

Acemoglu, D., F. A. Gallego and J. A. Robinson (2014), 'Institutions, Human Capital, and Development', Annual Review of Economics, 6: 875-912.

Acemoglu, D., S. Johnson and J. A. Robinson (2001), 'The Colonial Origins of Comparative Development: An Empirical Investigation', American Economic Review, 91(5): 1369-1401.

Acemoglu, D., S. Johnson and J. A. Robinson (2002), 'Reversal of Fortune: Geography and Institutions in the Making of the Modern World Income', Quarterly Journal of Economics, 117(4): 1231-1294.

Acemoglu, D., S. Johnson and J. A. Robinson (2005), 'The Rise of Europe: Atlantic Trade, Institutional Change, and Economic Growth', American Economic Review, 95(3): 546-579.

Ádam, Z. (2020), 'Re-feudalizing Democracy: An Approach to Authoritarian Populism Taken From Institutional Economics', Journal of Institutional Economics, 16(1): 105-118.

Algan, Y., S. Guriev, E. Papaioannou and E. Passari (2017), The European Trust Crisis and the Rise of Populism, Brookings Papers on Economic Activity, pp.309-382.

Aron, J. (2000), 'Growth and Institutions: A Review of the Evidence', World Bank Research Observer, 15(1): 99-135.

Boeri, T., P. Mishra, C. H. Papageorgiou and A. Spilimbergo (2018), Populism and Civil Society, IMF Working Paper, WP/18/245.

Boettke, P. J., C. J. Coyne and P. T. Leeson (2008), 'Institutional Stickiness and the New Development Economics', American Journal of Economics and Sociology, 67(2): 331-358.

Camussi, S. and A. L. Mancini (2019), 'Individual Trust: Does Quality of Local Institutions Matter?', Journal of Institutional Economics, 15(3): 487-503.

Casson, M. C., M. Della Giusta and U. S. Kambhampati (2010), 'Formal and Informal Institutions and Development', World Development, 38(2): 137-141.

Cervellati, M., P. Fortunato and U. Sunde (2008), 'Hobbes to Rousseau: Inequality, Institutions and Development', 118(531): 1354-1384.

Chavance, B. (2008), 'Formal and Informal Institutional Change: The Experience of Postsocialist Transformation', European Journal of Comparative Economics, 5(1): 57-71.

Chavance, B. and E. Magnin (2000), 'National Trajectories of Post-Socialist Transformation: Is There a Convergence Towards Western Capitalisms?', in M. Dobry (ed), Democratic and Capitalist Transitions in Eastern Europe, Dordrecht: Springer, pp. 221-233. 
Chong, A. and M. Gradstein (2018), 'Imposed Institutions and Preferences for Redistribution', Journal of Institutional Economics, 14(1): 127-156.

Chong, A. and M. Gradstein (2019), 'Institutional Persistence, Income Inequality, and Individual attitudes', Journal of Economic Inequality, 17(3): 401-413.

Christensen, T. and P. Lægreid (2005), 'Trust in Government: The Relative Importance of Service Satisfaction, Political Factors, and Demography', Public Performance \& Management Review, 28(4): 487-511.

Cruz-García, P. and J. Peiró-Palomino (2019), 'Informal, Formal Institutions and Credit: Complements or Substitutes?', Journal of Institutional Economics, 15(4): 649-671.

Democracy Index. (2019), The Economist Intelligence Unit, https://www.eiu.com/topic/democracy-index (accessed 20.10.2020)

Eggertsson, T. (2006), 'On the Survival of Imperfect Institutions', Revista de Analisis Economico, 21(2): 13-24.

Eicher, T. S. and O. Rohn (2007), 'Institutional Determinants of Economic Performance in OECD Countries - An Institutions Climate Index', CESifo DICE Report, 5(1): 38-49.

EVS. (2020), European Values Study 2017: Integrated Dataset (EVS 2017), GESIS Datenarchiv, Köln, ZA7500 Datenfile Version 3.0.0.

Glaeser, E. L., R. La Porta, F. Lopez-de-Silanes and A. Shleifer (2004), 'Do Institutions Cause Growth?', Journal of Economic Growth, 9(3): 271-303.

Google LLC. (2020), Google COVID-19 Community Mobility Reports. https://www.google.com/covid19/mobility/ (accessed: 08.02.2021).

Gradstein, M. (2008), 'Institutional Traps and Economic Growth', International Economic Review, 49(3): 1043-1066.

Guiso, L., H. Herrera, M. Morelli and T. Sonno (2017), Demand and Supply of Populism, EIEF Working Paper 17/03

Hale, T., N. Angrist, E. Cameron-Blake, L. Hallas, B. Kira, S. Majumdar, A. Petherick, T. Phillips, H. Tatlow and S. Webster (2020), Variation in Government Responses to COVID-19, Version 7.0, Blavatnik School of Government Working Paper; dataset (accessed: 27.01.2021).

Helmke, G. and S. Levitsky (2004), 'Informal Institutions and Comparative Politics: A Research Agenda', Perspectives on Politics, 2(4): 725-740.

Hodgson, G. M. (2003), 'The Hidden Persuaders: Institutions and Individuals in Economic Theory', Cambridge Journal of Economics, 27(2): 159-175.

Hodgson, G. M. (2006), 'What Are Institutions?', Journal of Economic Issues, 40(1): 1-25.

Holcombe, R. G. and C. J. Boudreaux (2016), 'Market Institutions and Income Inequality', Journal of Institutional Economics, 12(2): 263-276.

Knack, S. and P. Keefer (1995), 'Institutions And Economic Performance: Cross-Country Tests Using Alternative Institutional Measures', Economics and Politics, 7(3): 207-227.

Knack, S. and P. Keefer (1997), 'Does Social Capital Have an Economic Payoff? A Cross-Country Investigation', Quarterly Journal of Economics, 112(4): 1251-1288.

Kovac, M. and R. Spruk (2016), 'Institutional Development, Transaction Costs and Economic Growth: Evidence From a Cross-Country investigation', Journal of Institutional Economics, 12(1): 129-159.

Kuncic, A. (2014), 'Institutional Quality Dataset', Journal of Institutional Economics, 10(1): 135-161.

Kyriacou, A. P. and F. J. Lopez Velasquez (2015), 'Inequality and Culture in a Cross-Section of Countries', Journal of Institutional Economics, 11(1): 141-166.

Leković, V. (2011), 'Interaction of Formal and Informal Institutions - Impact on Economic Success', Economics and Organization, 8(4): 357-370.

North, D. C. (1994), Institutions, Institutional Change and Economic Performance, New York: Cambridge University Press.

North, D. C. (2005), Understanding the Process of Economic Change, Princeton: Princeton University Press.

Ostrom, E. (1990), Governing the Commons: The Evolution of Institutions for Collective Action, Cambridge: Cambridge University Press.

Ostrom, E. (2000), 'Collective Action and the Evolution of Social Norms', Journal of Economic Perspectives, 14(3): 137-158.

Ostrom, E. (2005), Understanding Institutional Diversity, Princeton: Princeton University Press.

Ostrom, E., J. Walker and R. Gardner (1992), 'Covenants With and Without a Sword: Self-Governance is Possible', American Political Science Review, 86(2): 404-417.

Ostrom, E., J. Burger, C. B. Field, R. B. Norgaard and D. Policansky (1999), 'Revisiting the Commons: Local Lessons, Global Challenges', Science, 284(5412): 278-282.

Our World in Data. (2020), Data on COVID-1. https://ourworldindata.org/coronavirus (accessed 03.02.2021)

Pejovich, S. (1999), 'The Effects of the Interaction of Formal and Informal Institutions on Social Stability and Economic Development', Journal of Markets \& Morality, 2(2): 164-181.

Platje, J. (2008), “Institutional Capital” as a Factor of Sustainable Development - the Importance of an Institutional equilibrium', Technological and Economic Development of Economy, 14(2): 144-150.

Rodrik, D., A. Subramanian and F. Trebbi (2004), 'Institutions Rule: The Primacy of Institutions over Geography and Integration in Economic Development', Journal of Economic Growth, 9(2): 131-165. 
Rothstein, B. and D. Stolle (2008), 'The State and Social Capital: An Institutional Theory of Generalized Trust', Comparative Politics, 40(4): 441-459.

Searle, J. (2005), 'What is an Institution?', Journal of Institutional Economics, 1(1): 1-22.

Sonin, K. (2003), 'Why the Rich may Favor Poor Protection of Property Right', Journal of Comparative Economics, 31(4): 715-731.

Tabellini, G. (2010), 'Culture and Institutions: Economic Development in the Regions of Europe', Journal of the European Economic Association, 8(4): 677-716.

The Legatum Prosperity IndexTM. (2019), Prosperity Rankings: Full 2019 Data set, https://www.prosperity.com/about/ resources (accessed 03.06.2020).

Timbro. (2019), Authoritarian Populism Index, https://populismindex.com/report/ (accessed 02.03.2020).

Voigt, S. (2013), 'How (Not) to Measure Institutions', Journal of Institutional Economics, 9(1): 1-26.

Voigt, S. (2018), 'How to Measure Informal Institutions', Journal of Institutional Economics, 14(1): 1-22.

Williamson, O. E. (2000), 'The New Institutional Economics Taking Stock Looking Ahead', Journal of Economic Literature, 38(3): 595-613.

Williamson, C. R. (2009), 'Informal Institutions Rule: Institutional Arrangements and Economic Performance', Public Choice, 139(3/4): 371-387.

Williamson, C. R. and C. B. Kerekes (2011), 'Securing Private Property: Formal versus Informal Institutions', Journal of Law \& Economics, 54(3): 537-572.

Zak, P. J. and S. Knack (2001), 'Trust and Growth', Economic Journal, 111(470): 295-321.

Cite this article: Bentkowska K (2021). Response to governmental COVID-19 restrictions: the role of informal institutions. Journal of Institutional Economics 17, 729-745. https://doi.org/10.1017/S174413742100028X 